\title{
Psycho-Physiological Combined Therapy on the Sexual Desire*
}

\author{
Roohallah Bay ${ }^{1 \#}$, Shaiful Bahari Ismail ${ }^{2}$, Fatemeh Bay ${ }^{3}$ \\ ${ }^{1}$ Sexual and Family Therapy Group, Department of Family Medicine, School of Medical Sciences, \\ Universiti Sains Malaysia (USM), Kelantan, Malaysia \\ ${ }^{2}$ Department of Family Medicine, Universiti Sains Malaysia (USM), Kelantan, Malaysia \\ ${ }^{3}$ Department of Psychology and Educational Sciences, Kharazmi University, Tehran, Iran \\ Email: \#ir_psychology@yahoo.com
}

Received August 7, 2013; revised September 7, 2013; accepted September 15, 2013

Copyright (C) 2013 Roohallah Bay et al. This is an open access article distributed under the Creative Commons Attribution License, which permits unrestricted use, distribution, and reproduction in any medium, provided the original work is properly cited.

\begin{abstract}
Objective: Hypoactive Sexual Desire is characterized as a lack or absence of sexual fantasies and desire for sexual activity. The current study examines the effects of psycho-physiological therapy (stretch therapy combined with breathing exercise) on the sexual desire among heterosexual men. Methods: We used "convenience sampling” for this research; 80 people were recruited. For collection of data, we used an identical quasi-experimental design called "nonequivalent control group.” Therapy sessions each lasting (20) 90 to $120 \mathrm{~min}$ were carried out on 3 alternate days of week. The volunteers have been selected from heterosexual men with stable relationship, those who married minimum of 6 months, within 20 to 55 years old, who attended to HUSM Family Clinic. Pre-tests, post-tests, and follow-up tests were conducted in a HUSM clinic (Malaysia). For assessment we used Hurlbert Index of Sexual Desire (HISD). Results: The psycho-physiological group had better post-test scores compared to the control group. Also follow-up test scores were marginally better compared to the control group, but this difference did not reach statistical significance. Also age and education level of participants didn't have any significant effect on this intervention. Conclusion: Psycho-physiological combined therapy including stretching and breathing exercise appears to result in better improvement in sexual desire compared to control group but this improvement is not great. It increases sexual desire of heterosexual men, whenever people follow the therapy.
\end{abstract}

Keywords: Combined Therapy; Sex; Desire

\section{Introduction}

Hypoactive sexual desire is considered as a sexual dysfunction and is listed under the Sexual and Gender Identity Disorders of the DSM-IV. It is characterized as a lack or absence of sexual fantasies and desire for sexual activity for some period of time [1].

During the last few decades, marital tensions and stresses have influenced various dimensions of life. Studies done on married persons compatible with marital life show that they live largely with healthy food, body and nutrition and thus suffered less from psychological difficulties [2].

At the root of a couple's argument over a day to day, mundane matter is often the need for intimate contact. This is not to say that sexual intercourse is a panacea for

*This study was supported by USM SHORT TERM GRANT from the Universiti Sains Malaysia from the Health Campus, School of Medical Sciences.

"Corresponding author. all problems couples encountering in life. However, the desire of the need for intimate contact inclusive of some form of physical contact is fundamental to personal health and in fact fundamental to human nature. Sex is an individual psychological event, and the attitudes of the individual. His/her earlier experience, anxiety, tiredness and overwork can all have a major damaging effect on sex [3].

It is evident that in direction to confront these difficulties, prevention and training and reform are very important in order to increase knowledge \& power of people in correct \& suitable reaction with life events. At present, paying attention to current relationship in marital and family life \& its sexual relationship in order to overcome this problem is among the most important steps.

There are clear evidences that from the first of 1980, psychotherapy has grown very fast towards integration. This movement puts the best approach together to make a better \& more complete treatment model [4]. 
Within this way, psycho-physiological sex-therapy is one of the new alterative and complementary therapies in order to keep saving marriage and increasing society welfare.

Sex therapy is the result of relatively recent scientific attention to human sexual function and dysfunction. Increased knowledge of physiology and psychology of human sexual behavior brought a new professional appreciation for human sexual response. At a time in our society, when sexuality is being more openly discussed, we are beginning to realize how uninformed, many people, really are about this important personal topic. Sex therapy can be helpful for individuals and couples depending on the issue being addressed. Some issues can be dealt with on an individual basis, while others are best treated in the context relationship of a couple [5].

Now considering the above-mentioned, this research is going to investigate the effectiveness of psycho-physiological combined therapy (Stretch Therapy combined Breathing Exercise) on the Sexual desire in Heterosexual Men.

Currently, stretch therapy is increasing in the United States, where 10 - 15 million people participate in stretching classes [6]. In 1997, more than $40 \%$ of people living in the United States had practiced at least one type of complementary or alternative therapy; psycho-physiological stretch therapy is one of the modalities included in this term [7]. Finally, 65\% of people receiving mental health services engage in one type of modality of alternative or adjunctive therapy [8].

The findings have described possible benefits of stretching to protect mental health. Specifically the literature suggests that some style of them such as yoga may be related to an increase in coping skills, and self-esteem, and a decrease stress, anxiety, and depression [9-12].

Research has shown that some kinds of breathing exercises such as Bhasrika help in treatment. They affect mind, brain and nervous system and increase oxygen levels and reduce carbon dioxide levels in the blood. In these breathing styles, the abdominal muscles and diaphragm are used which put pressure on the internal organs. Also, Regular practice of breathing exercises will ensure proper oxygenation of all parts of the body and cure many diseases. Proper oxygenation helps purify the blood and removal of toxins and carbon dioxide from the body [13].

Stretching and the improvement of flexibility have been an important goal both in the recreational and therapeutic field in the belief that it is beneficial in promoting good physical and mental function [14-17]. It is claimed that stretching can reduce injury risk, relax hypertonic muscles, lengthen shortened tissue [18,19], and help improve faulty posture $[15,20,21]$. In spite of its constant use and clinically observable results, the research remains somewhat controversial in determining how effective stretch- ing is, and indeed how stretching achieves its effects. Utilizing various movement philosophies, for example Proprioceptive Neuromuscular Facilitation (PNF) [22], Feldenkrais1 [23], Pilates [24], and Tai Chi [25], can help restore or improve flexibility, decrease pain and improve coordination, thereby improve overall function. The following article and ensuing articles by different authors will attempt to review and explain some basic facts, philosophies and observations regarding flexibility and how and why it is of such clinical importance.

The purpose of this study was to address 1 main hypothesis and 2 minor hypotheses. The main hypotheses of this research are to evaluate if psycho-physiological combined therapy (Stretch Therapy combined Breathing Exercise) has an effect on the Sexual desire among Heterosexual Men and if a difference exists between the effects of psycho-physiological combined therapy (Stretch Therapy combined Breathing Exercise) and those of control group on the Sexual desire. The minor hypotheses are to test if differences exist between the effects of psycho-physiological combined therapy (Stretch Therapy combined Breathing Exercise) and control group on the Sexual desire among Heterosexual Men when (1) age, and (2) education level, are considered either individually or as a whole.

\section{Material and Methods}

In this research, the independent variable is psycho-physiological combined therapy (Stretch Therapy combined Breathing Exercise), and the dependent variable is the sexual desire of heterosexual men. The therapy schedule, gender (only Male), Co morbidities (Stable, Non-Cardiac and without Prostatic Disease), social, economic and cultural factors, the location and the environment of therapy, and the therapist are control variables. Moderator variables are education level and age (we would study the subjects in 2 part of age: 20 - 35 and 36 - 55).

\section{Intervention Therapy Methods}

\section{Psycho-Physiological Combined Therapy:}

For this research, we used Static Stretching and Breathing Exercise techniques to make an integration therapy. Static stretching involves a muscle that is slowly and passively stretched to full range, continued tension is then maintained for an extended period of time e.g. $2 \pm$ $15 \mathrm{~min}$, to further increase its length. For maximum gains, it is important that the person stretching waits until the muscles relax in the assumed position.

Each one of treatment session will start with 10 minute warming up and rhythmic breathing (10 Sec inhales, 25 Sec blocking the breath, $15 \mathrm{Sec}$ exhales, and $10 \mathrm{Sec}$ blocking the breath) techniques. Then, we will continue with Stretch Therapy. Each muscle would be stretched 
separately. And all of the surfaces muscles would be stretched. Patient should exhale, when muscle would be stretched, and patients should inhale, when it would be released. And ultimately, we would finish each session with rhythmic breathing techniques and 5 minute warming down. In this research program, we consider twenty (20) 90 - 120 minutes session.

\section{Materials and Research Methodology}

Our samplegroups of 80 heterosexual men were selected from volunteers who were registered at who visited HUSM clinic of Kotabharu (Kelantan, Malaysia). We used "Convenience Sampling” about this point. The volunteers have selected from heterosexual men with stable relationship, those who married minimum of 6 months, within 20 to 55 years old, who attended to HUSM Family Clinic. For data collection, we used quasi-experimental designs called "non-equivalent control group.” Pre-tests were done on both groups before intervention began, post-tests were done after intervention had been completed, and follow-up tests were done 1 month after the last session.

For the setting, we used a hall at Men's Health clinic at HUSM. For the experimental group, we conducted ten (20) 90 to 120 minute meetings on 3 alternate days of week, while for the control group, we left them to follow own ordinary life. We conducted this program for 20 sessions and had 3intervention session every week.

To measure the effects of intervention, we used pretests, post-tests and follow-up tests. Also Cardiac Patients, Uncontrolled Types 1 and 2 Diabetic Patients, HbA1c < 8.5\%, Patient with Prostatic Disease, Major Uncontrolled Psychiatric Disorders, Chronic arthritis, History of alcohol or drug abuse and Clinically significant baseline laboratory abnormality have been as Subject Exclusion Criteria; And Signed informed Consent, Heterosexual Married Men minimum of 6 months and aged $>20$ and $<50$ years as Subject Inclusion Criteria.

\section{Statistical Methods}

Data entry and statistical analyses were done using SPSS version 19. In descriptive statistics, we used the mean and standard deviation (SD), as well as tables and charts. In inferential statistics, in order to compare the data, we used Repeated Measure ANOVA.

For assumption checks, we examine the residuals for normality and equality of variances. On examination of histogram of residuals, all of them are normally distributed. Extend of spread of error variances by each level looked similar, so assumption of equal variances met. Further, the Levene's test was not significant, so assumption of equal variances assumed.

\section{Procedure}

We announced this research at hospital and clinics of Universiti Sains Malaysia (Kelantan). Then, the volunteers for this research were asked to complete forms to get information about the volunteers' ages, genders, drugs used, education levels, other illnesses that they suffered, etc. This information was necessary both to form similar groups to prevent obstructive variable effects and to manage the control and the moderator variables, as well as the obstructive factors.

Initially, we had 150 volunteer heterosexual men. Then, by paying attention to the control and moderator variables and trying to decrease obstructive variables, we invited them for interviews and checkups. We, the time of the interviews, researcher obtained information on the patients' backgrounds, durations of disease, kinds of medicines used, and nutrition with lists of daily meals, and etc. Then, according to the research design (unequal control groups), we made an experimental group and one control group. Ultimately, from the 100 patients, we placed 80 people in both groups randomly.

The duration for all therapy sessions was around 90 to 120 minutes, and we conducted 20 therapy sessions for each of the volunteers in the experimental group. It is important to note that before starting the therapy sessions, all of the volunteers (both the placebo and the experimental groups) went to the HUSM clinic to medical checkup. Then before starting the therapy sessions, we made pre-test on all of the volunteers (both the control and the experimental groups).

For the experimental group's patients, we conducted psychophysiological combined therapy (stretching therapy combined with breathing exercise) during each session on 3 alternate days per week. At the end of therapy, for both the experimental and control group's we made post-test. Then, we left the experimental group to get back ordinary life too. Around one month after finishing the therapy sessions, on a specified day, we made follow-up test on all patients of both groups, to get how long the effect of therapy would remain.

\section{Assessment}

In order to assessment of sexual desire, we used Hurlbert Index of Sexual Desire (HISD) [26].

\section{Results}

Data shown P value Mauchly's Test is less than 0.05 (0.000) and Epsilon Greenhouse-Geisser is more than 0.75 (0.830); so we have to read Greenhouse-Geisser from within subject effect table.

As you see in Table 1, the time $\mathrm{P}$ value is 0.122 . it means some changes have happened with passing time 
Table 1. Tests of within subjects effects.

\begin{tabular}{ccccc}
\hline & Source & df & F & Sig. \\
\hline Time & Greenhouse-Geisser & 1.660 & 2.222 & 0.122 \\
Time*Group & Greenhouse-Geisser & 1.660 & 8.077 & 0.001 \\
Time*Group*Age & Greenhouse-Geisser & 1.660 & 1.999 & 0.148 \\
Time*Group*Education & Greenhouse-Geisser & 1.660 & 0.219 & 0.763 \\
\hline
\end{tabular}

but statistically it is not significant. The time and group $\mathrm{P}$ value is significant (0.001). It means some change happened in groups with passing time.

Also as you see in Table 2, the group P value is 0.434 . There is no difference between the groups regardless of time.

In order to get the quantity of changing, we should get the details from Estimate Marginal Mean data.

As you see in Table 3, experimental group Estimate Marginal Mean data shows pretest sexual desire has been 54.637 and in posttest it increased to 63.216 and ultimately in follow-up test it change to 63.444.

Simultaneously control group Estimate Marginal Mean data shows pretest sexual desire has been 65.467 and in posttest it decreased to 62.933 and ultimately in follow-up test it change to 62.583 .

If you compare posttest and follow-up test mean score of experimental group (63.216 and 63.444) with pretest lower to upper bound range (48.305 - 60.969) you would find the experimental group changing in posttest is significant. But you couldn't find same situation in control group. It means experimental group got improvement within combined psycho-physiological therapy.

As you see in Table 1, the time, group and age $\mathrm{P}$ value is 0.148 . It means the age has had some effects on groups with passing Time but statistically the effect differentiation is not significant.

Also as you see in Table 2, the group and age P-value (between groups) is not significant (0.478). It mean we can say regardless to time, statistically age has had no effect on groups.

In order to get the quantity of changing, we should get the details from Estimate Marginal Mean data. As you see in Table 4, experimental group Estimate Marginal Mean data shows age group 1 (20 - 35) pretest sexual desire has been 52.417 and in posttest it increased to 66.194 and ultimately in follow-up test it change to 67.889 .

And Estimate Marginal Mean data shows age group 2 (36 - 55) pretest sexual desires have been 56.857 and in posttest it increased to 60.238 and ultimately in followup test it change to 59.000 .

Simultaneously control group Estimate Marginal Mean data shows age group 1 (20 - 35) pretest sexual desire has been 64.000 and in posttest it decreased to 61.900 and ultimately in follow-up test it change to 61.500.
Table 2. Tests of between subjects effects.

\begin{tabular}{cccc}
\hline Source & df & F & Sig. \\
\hline Group & 1 & 0.619 & 0.434 \\
Group*Age & 1 & 0.509 & 0.478 \\
Group*Education & 1 & 0.213 & 0.646 \\
\hline
\end{tabular}

Table 3. Group*time.

\begin{tabular}{cccccc}
\hline \multirow{2}{*}{ Group } & \multirow{2}{*}{ Time } & & \multirow{2}{*}{ Mean } & Std. Error & \multicolumn{2}{c}{$95 \%$ Confidence Interval } \\
\cline { 3 - 6 } Experimental & 1 & 54.637 & 3.173 & 48.305 & 60.969 \\
& 2 & 63.216 & 2.784 & 57.661 & 68.772 \\
& 3 & 63.444 & 3.206 & 57.047 & 69.842 \\
& 1 & 65.467 & 3.450 & 58.583 & 72.350 \\
Control & 2 & 62.933 & 3.027 & 56.893 & 68.973 \\
& 3 & 62.583 & 3.486 & 55.628 & 69.539 \\
\hline
\end{tabular}

And Estimate Marginal Mean data shows age group 2 (36 - 55) pretest sexual desire has been 66.933 and in posttest, it decreased to 63.967 and ultimately in followup test it change to 63.667 .

As you see in Table 1, the time, group and education $\mathrm{P}$ value is 0.763 . It mean the education level have had some effects on groups with passing Time but statically the effect differentiation is not significant.

Also as you see in Table 2, the group and Education $\mathrm{P}$ value (between groups) is not significant (0.646). It means we can say regardless to time, statically education has had no effect on groups.

In order to get the quantity of changing, we should get the details from Estimate Marginal Mean data. As you see in Table 5, experimental group Estimate Marginal Mean data shows education group 1 (primary-secondary) pretest sexual desire has been 55.940 and in posttest it increased to 65.488 and ultimately in follow-up test it changed to 64.667 .

And Estimate Marginal Mean data shows education group 2 (tertiary) pretest sexual desires has been 53.333 and in posttest it increased to 60.944 and ultimately in follow-up test it change to 62.222.

Simultaneously control group Estimate Marginal Mean data shows education group 1 (primary-secondary) pretest sexual desire has been 69.100 and in posttest it decreased to 65.867 and ultimately in follow-up test it change to 66.500 .

And Estimate Marginal Mean data shows education group 2 (tertiary) pretest sexual desire has been 61.833 and in posttest, it decreased to 60.000 and ultimately in follow-up test it change to 58.667.

\section{Discussion}

Approximately $35 \%$ of all family medicine departments 
Table 4. Group*age*time.

\begin{tabular}{|c|c|c|c|c|c|c|}
\hline \multirow{2}{*}{ Group } & \multirow{2}{*}{ Age } & \multirow{2}{*}{ Time } & \multirow{2}{*}{ Mean } & \multirow{2}{*}{ Std. Error } & \multicolumn{2}{|c|}{ 95\% Confidence Interval } \\
\hline & & & & & Lower Bound & Upper Bound \\
\hline \multirow{6}{*}{ Experimental } & \multirow{3}{*}{$20-35$} & 1 & 52.417 & 2.905 & 46.619 & 58.214 \\
\hline & & 2 & 66.194 & 2.549 & 61.108 & 71.281 \\
\hline & & 3 & 67.889 & 2.936 & 62.031 & 73.747 \\
\hline & \multirow{3}{*}{$36-55$} & 1 & 56.857 & 5.642 & 45.599 & 68.115 \\
\hline & & 2 & 60.238 & 4.950 & 50.360 & 70.116 \\
\hline & & 3 & 59.000 & 5.701 & 47.624 & 70.376 \\
\hline \multirow{6}{*}{ Control } & \multirow{3}{*}{$20-35$} & 1 & 64.000 & 6.038 & 51.951 & 76.049 \\
\hline & & 2 & 61.900 & 5.298 & 51.328 & 72.472 \\
\hline & & 3 & 61.500 & 6.101 & 49.325 & 73.675 \\
\hline & \multirow{3}{*}{$36-55$} & 1 & 66.933 & 3.338 & 60.273 & 73.594 \\
\hline & & 2 & 63.967 & 2.929 & 58.123 & 69.811 \\
\hline & & 3 & 63.667 & 3.373 & 56.937 & 70.397 \\
\hline
\end{tabular}

Table 5. Group*education*time.

\begin{tabular}{|c|c|c|c|c|c|c|}
\hline \multirow{2}{*}{ Group } & \multirow{2}{*}{ Education } & \multirow{2}{*}{ Time } & \multirow{2}{*}{ Mean } & \multirow{2}{*}{ Std. Error } & \multicolumn{2}{|c|}{ 95\% Confidence Interval } \\
\hline & & & & & Lower Bound & Upper Bound \\
\hline \multirow{6}{*}{ Experimental } & \multirow{3}{*}{ primary_secondary } & 1 & 55.940 & 2.552 & 50.849 & 61.032 \\
\hline & & 2 & 65.488 & 2.239 & 61.021 & 69.956 \\
\hline & & 3 & 64.667 & 2.578 & 59.522 & 69.812 \\
\hline & \multirow{3}{*}{ tertiary } & 1 & 53.333 & 5.810 & 41.739 & 64.928 \\
\hline & & 2 & 60.944 & 5.098 & 50.772 & 71.117 \\
\hline & & 3 & 62.222 & 5.871 & 50.507 & 73.938 \\
\hline \multirow{6}{*}{ Control } & \multirow{3}{*}{ primary_secondary } & 1 & 69.100 & 2.663 & 63.787 & 74.413 \\
\hline & & 2 & 65.867 & 2.336 & 61.205 & 70.528 \\
\hline & & 3 & 66.500 & 2.690 & 61.131 & 71.869 \\
\hline & \multirow{3}{*}{ tertiary } & 1 & 61.833 & 6.365 & 49.132 & 74.534 \\
\hline & & 2 & 60.000 & 5.585 & 48.856 & 71.144 \\
\hline & & 3 & 58.667 & 6.431 & 45.833 & 71.500 \\
\hline
\end{tabular}

offer some kind of instruction in alternative therapies. According to Bricklin, approximately $40 \%$ of the US population is found to be using alternative therapies [27]. As popular interest in alternative medicine has increased, so has advanced practical nurse involvement, research attention and the likelihood of insurance reimbursement. Research interest in alternative therapies at the National Institute of Health is growing. The Organization of Alternative Medicine (OAM) has recently funded a study of alternative therapies at several academic centers, including, among others, Harvard, Stanford and Columbia medical schools. Meanwhile, managed care organizations and insurance companies, including Mutual of Omaha, Blue Cross/Blue Shield of Washington and Alaska, and U.S. Health Care, are offering special health plans that include alternative therapies [27].

We hypothesized that combined psycho-physiological therapy (Stretch therapy combined breathing exercise) have effect in self-reported sexual desire compared to control group. Consistent with our hypotheses, psychophysiological group achieved greater improvements in sexual desire compared to participants in control group. We observed a trend towards greater improvements in sexual desire for psycho-physiological therapy group compared to participants in control group, but this difference did not reach statistical significance. Overall, these findings provide support for the beneficial effects of combined psycho-physiological therapy (Stretch therapy combined breathing exercise) on sexual desire for 20 - 55 years old heterosexual men. Also the data had shown that age and education doesn't have any significant effect in the psycho-physiological intervention.

Several studies suggest that higher levels of physical activity are associated with improved sexual function [28-30]. In a 2006 meta-analysis, Cheng et al. observed a dose-response relationship between levels of physical activity and ED, with higher levels of activity predicting lower risk of ED and vice versa [31]. In a cross-sectional 
study of 1506 men in Hong Kong, Cheng and Ng (2007) determined that greater self-reported physical activity (expressed as energy expenditure per month) was associated with lower levels of self-reported ED, particularly among men who were overweight. Esposito et al. (2004) randomly assigned 110 obese men with ED either to a two-year diet and physical activity group intervention, or to an education control group. After two years, the intervention group reported better erectile function compared to the control group. Furthermore, increased physical activity was associated with improvements in ED, independent of weight loss. Relationships between physical activity and sexual dysfunction have not been studied as thoroughly in women. One study by Wilbur et al. examined the effects of a 24-week moderate intensity walking program on menopausal symptoms, including uro-genital symptoms of vaginal dryness, irritation, decreased sexual desire, and pain during intercourse. This study did not show significant improvements in uro-genital symptoms in the walking group as compared to the control group. However, adherence was low in the walking group [32].

Shapiro \& Cline [33] also evaluated the effect of stretching and breathing exercise on mood. Participants were eight women and three men, ages 23 to 59. There was no control group. Results indicated significant changes for 9 out of the 15 moods including a decrease in anxiety, frustration, stress, and fatigue and an increase in feeling content, happy, optimistic, and relaxed.

Arpita suggested that stretch and breathing exercise such as yoga may lead to physiological balance, a decrease in psychological distress, and an increase in selfesteem. Vahia, Vinekar, and Donngaji (1966) studied 30 hospital patients with a range of diagnoses including depression, peptic ulcer, schizophrenia, and anxiety reaction disorder. Treatment consisted of stretching postures, philosophy, breathing techniques, and meditation for an average of four to six weeks. Patients attended classes six days a week for one-half hour to an hour. Results indicated that patients suffering from anxiety and depressive disorders showed a decrease in symptoms [34].

Our study supports a link between alternative healing therapies and increase in mean sexual desire. This creates a need for structured programs teaching lifestyle change, non-pharmacologic interventions and alternative therapies in conjunction with conventional treatment. Alternative therapies can be extremely useful adjuncts to conventional care, and they sometimes provide the most appropriate treatment for treat conditions, such as sexual desire, erection disorder and sexual satisfaction.

The psychological role has always been one of patients' advocates. If lifestyle changes and alternative healing, such as stretch therapy combined breathing exercise, are taught to patients, the risk of sexual problems and its other side effects on family life will decrease. Pharma- cologic treatment is an area of expertise that requires special attention in family problems population. However, there can be adverse side effects with medication. By implementing holistic healing classes, the therapist can give patients the foundation to reduce stress in their lives, thereby reducing the need for conventional medical treatment. Therapist can also experience both the benefits and the limitations of these approaches and find ways to use them with their patients. By embarking on these extended courses of study, the clinical results may justify the investment of time and energy [35].

The findings of our study have implications for advanced psycho-physiological practice, education and health care of low sexual desire patients and for others who suffer from sexual problems. The implementation of psycho-physiological therapy (stretch therapy combined breathing exercise) classes taught by a psycho-physiologist in the outpatient clinic should be considered at the patient's first clinic visit. A shift in emphasis from treating to teaching highlights the psychological function as a guide and teacher and makes patient care a more fulfilling partnership. All psychologists should have knowledge of holistic healing and implementation of psychophysiological therapy (stretch therapy combined breathing exercise) as classes in schools of psychology will introduce the concept of alternative healing therapies [36].

Our study has raised questions and has impacted other areas. Alternative and combined therapies suggest a wider vision of what medicine can and should be through appreciation of the interconnectedness of mind and body, emphasis on enhancing the body's own capacity for healing and the use of the entire world's healing traditions. Alternative therapies can be used as an adjunct to treat all disease states of the mind and body. It is entirely possible that in less than a generation, the approach and techniques currently called "alternative" will be an integral part of the practice of all family and sex therapist, psycho-physiology and neuro-psychology practitioners.

Our study established combined psycho-physiological therapy (stretch therapy combined breathing exercise) as important to the family and sexual problem patient populations as it provides the patient with the power to decrease stress and to enhance the body's own capacity for healing. Integration of stretch therapy and breathing exercise in treatment plans allows a collaborative and democratic relationship between the advanced psychophysiological practitioner, other health providers, and the patient, who then reaps the psychological and physiological rewards of feeling more in control of their own lives.

\section{Limitations}

These results are unique to this trial, and will need to be 
replicated in future research. In this research, the sample size may not be representative, as samples would only be from Kota Bharu (Kelantan-Malaysia) and within limited time frame, so future researchers are encouraged to extend these results to other populations, and to continue to pursue research on sexual dysfunction and marital satisfaction.

In this research, we had to get the sample from voluntaries who would like to attend for this intervention, and then we placed these people in groups randomly. But after analyzing we got the group base lines, which haven't been completely the same. It seems experimental group voluntaries, who had more motivation to attend in experimental group, already have had some more difficult situations or they were feeling to have more problems in comparing voluntaries of control group. That's why we can find clear differences among scores and tests of groups but because of mentioned cause, these differences statistically are not significant, although it is clear that the intervention has had good effect on experimental group, if you check the results and mean scores of groups. So it is suggested that following future and similar researches should pay attention to motivation of voluntaries and try to use other methods of sampling.

Also, additional research is needed for mechanisms by which psycho-physiological exercise and treatment improve family and sexual functioning, with an emphasis on other populations and women.

\section{Acknowledgements}

This study was supported by USM SHORT TERM GRANT from the University Sains Malaysia from the Health Campus, School of Medical Sciences.

\section{REFERENCES}

[1] J. Waite-Linda, "Why Marriage Matters," Strengthening Marriage Round Table, Washington DC, 1997.

[2] American Psychiatric Association, "Diagnostic and Statistical Manual of Mental Disorders-IV-Text Revision," 4th Edition, American Psychiatric Association, Washington DC, 2004.

[3] M. Crowe and J. Ridley, "Therapy with Couples: A Behavioral-Systems Approach to Couple Relationship and Sexual Problems,” Pub Black Well Science Ltd., Malden, 2006.

[4] M. R. Gold-Fried and L. G. Cstonguay, "The Future of Psychotherapy Integration,” Psychotherapy, Vol. 29, No. 1, 1992, pp. 4-10. http://dx.doi.org/10.1037/0033-3204.29.1.4

[5] D. M. Schnarch, "Sexual-Marital Therapy with Mature Couples,” Family Therapy News, New York, Vol. 26, No. 3, 1995.

[6] R. Corliss, “The Power of Yoga,” Electronic Version, Time Magazine, April 23, 2001.
[7] L. Eisenberg, "Complementary and Alternative Medicine: What Is Its Role?” In: A. P. Fishman and M. Hager, Eds., Education of Health Professionals in Complementary/ Alternative Medicine, Macy Foundation, New York, 2001, pp. 32-41.

[8] L. Bassman and G. Ullendahl, “Complementary/Alternative Medicine: Ethical, Professional, and Practical Challenges for Psychologists," Professional Psychology Research and Practice, Vol. 34, No. 3, 2003, pp. 264-270. http://dx.doi.org/10.1037/0735-7028.34.3.264

[9] Arpita, "Physiological and Psychological Effects of Hatha Yoga: A Review of the Literature," The Journal of the International Association of Yoga Therapists, Vol. 1, 2000, pp. 1-28.

[10] D Campbell and K. Moore, "Yoga as a Preventative and Treatment for Depression, Anxiety, and Stress,” International Journal of Yoga Therapy, Vol. 14, No. 1, 2004, pp. 53-58.

[11] D. Shapiro and K. Cline, "Mood Changes Associated with Iyengar Yoga Practices: A Pilot Study,” International Journal of Yoga Therapy, Vol. 14, 2004, pp. 35-44.

[12] A. Woolery, H. Myers, B. Sternlieb, L. Zeltzer, “A Yoga Intervention for Young Adults with Elevated Symptoms of Depression," Alternative Therapies, Vol. 10, No. 2, 2004, pp. 60-63.

[13] D. Vora, "Health in Your Hands,” Vol. 1, Navneet Publications Limited, Mumbay, 1898.

[14] J. C. Travell, D. G. Simons, "Myofascial Pain and Dysfunction: The Trigger Point Manual," Vol. 1-2, William and Wilkins, Baltimore, 1994.

[15] V. Janda and G. Jull, "Muscles and Motor Control In Low Back Pain: Assessment,” In: L. T. Twomey and J. R. Taylor, Eds., Physical Therapy of the Low Back, Churchill Livingstone, New York, 1987.

[16] V. Janda, "Muscles and Cervicogenic Pain Syndromes," In: R. Grant, Ed., Physical Therapy of the Cervical and Thoracic Spine, Churchill Livingstone, New York, 1988.

[17] B. H. Bunkan, "Muskel Spanningar," Under Sokning Ochbe Handling Liber, Stockholm, 1980.

[18] P. Markos, "Ipsilateral and Contralateral Effects of Proprioceptive Neuromuscular Facilitation Techniques on Hip Motion and Electromyographic Activity,” Physical Therapy, Vol. 59, No. 11, 1979, pp. 1366-1373.

[19] B. R. Etnyre and L. D. Abraham, "Gains in Range of Ankle Dorsiflexion Using Three Popular Stretching Techniques," American Physical Medicine, Vol. 65, No. 4, 1986, pp. 189-196.

[20] C. H. Wang, P. McClure, N. E. Pratt and R. Nobilini, "Stretching and Strengthening Exercises: Their Effect on Three Dimensional Scapular Kinematics," Archives of Physical Medicine and Rehabilitation, Vol. 80, No. 8, 1999, pp. 923-929.

[21] E. F. Wright, A. D. Domenech and J. R. Fischer, "Usefulness of Posture Training for Patients with Temporomandibular Disorders," Journal of the American Dental Association, Vol. 131, No. 2, 2000, pp. 202-210.

[22] M. A. More, “An Electromyographic Investigation of 
Muscle Stretching Techniques,” Unpublished Master's Thesis, University of Washington, Seattle, 1979.

[23] R. Ofir, "The Feldenkrais Method, the Importance and Potency of Small and Slow Movements," Physical Therapy Forum, Vol. 42, No. 5, 1990, pp. 3-5.

[24] K. Swaim, “An Alternative Therapy: Pilate’s Method,” PT Magazine, October 1993, pp. 55-58.

[25] S. L. Wolf, C. Coogler and T. Xu, "Exploring the Basis for Tai Chi Chuan as a Therapeutic Exercise Approach," Archives in Physical Medicine and Rehabilitation, Vol. 78, No. 8, 1997, pp. 886-892. http://dx.doi.org/10.1016/S0003-9993(97)90206-9

[26] C. Apt and D. F. Hurlbert, "The Sexuality of Women in Physically Abusive Marriages: A Comparative Study,” Journal of Family Violence, Vol. 8, No. 1, 1992, pp. 5769. http://dx.doi.org/10.1007/BF00986993

[27] M. Bricklin, "Positive Living and Health,” Rodale Press, Pennsylvania, 1990.

[28] C. G. Bacon, M. A. Mittleman, I. Kawachi, E. Giovannucci, D. B. Glasser and E. B. Rimm, "Sexual Function in Men Older Than 50 Years of Age: Results from the Health Professionals' Follow-Up Study,” Annals of Internal Medicine, Vol. 139, No. 3, 2003, pp. 161-168. http://dx.doi.org/10.7326/0003-4819-139-3-200308050-0 $\underline{0005}$

[29] K. Esposito and D. Giugliano, "Obesity, the Metabolic Syndrome, and Sexual Dysfunction,” International Journal of Impotence Research, Vol. 17, 2005, pp. 391-398. http://dx.doi.org/10.1038/sj.ijir.3901333

[30] K. Esposito, E. Giugliano, C. Di Palo, G. Giugliano, R. Marfella, E. D’Andrea, et al., "Effect of Lifestyle Changes on Erectile Dysfunction in Obese Men: A Randomized Controlled Trial,” JAMA, Vol. 291, No. 24, 2004, pp. 2978-2984. http://dx.doi.org/10.1001/jama.291.24.2978

[31] J. Y. Cheng, E. M. Ng, J. S. Ko and R. Y. Chen, "Physical Activity and Erectile Dysfunction: Meta-Analysis of Population-Based Studies,” International Journal of Impotence Research, Vol. 19, 2006, pp. 245-252. http://dx.doi.org/10.1038/sj.ijir.3901521

[32] J. Wilbur, A. M. Miller, J. McDevitt, E. Wang and J. Miller, "Menopausal Status, Moderate-Intensity Walking, and Symptoms in Midlife Women," Research and Theory for Nursing Practice, Vol. 19, No. 2, 2005, pp. 163-180.

[33] D. Shapiro and K. Cline, "Mood Changes Associated with Iyengar Yoga Practices: A Pilot Study,” International Journal of Yoga Therapy, Vol. 14, 2004, pp. 35-44.

[34] Arpita, "Physiological and Psychological Effects of Hatha Yoga: A Review of the Literature," The Journal of the International Association of Yoga Therapists, Vol. 1, 2000, pp. 1-28.

[35] R. Bay, "Alternative and Psycho-Physiological Complementary Therapies," Suchak Creations Publication, Pune, 2009.

[36] R. Bay, "Explanatory Dictionary of Type 2 Diabetes with Psycho-Physiological Treatments," Suchak Creations Publication, Pune, 2009. 